\title{
TENSIONES Y DESAFÍOS EN TORNO A LA MASIFICACIÓN DE LA ESCUELA SECUNDARIA. REFLEXIONES A PARTIR DE UNA PROPUESTA EDUCATIVA EN LA CIUDAD DE NEUQUÉN*
}

\author{
María Delfina Garino (CONICET. Universidad Nacional del Comahue)* \\ delgarino@gmail.com
}

Recibido: 31/07/2012 Aceptado: 1/10/2012

\section{Resumen}

Ni la masificación de la escuela secundaria en Argentina desde mediados del siglo XX, ni la obligatoriedad estipulada por ley desde 2002, conllevan una modificación de su formato escolar tradicional, caracterizado como selectivo y excluyente. Por el contrario, se crean algunas escuelas -y se transforman otras-cuyo propósito es incluir en sus aulas sectores sociales antes excluidos de este fragmento del sistema escolar.

En este artículo, nos proponemos trabajar en torno a las complejidades generadas a partir de esta situación, en la que se contraponen selección-masificación y exclusiónobligatoriedad, recuperando problematizaciones acerca del formato tradicional de la escuela secundaria y de las nuevas propuestas que surgen en este contexto. Para esto, analizaremos una propuesta pedagógica novedosa de una escuela secundaria de la ciudad de Neuquén que se propone incluir sectores de bajos recursos de la ciudad.

\section{Palabras claves}

Escuela secundaria - formato escolar - masificación - selección - inclusión.

\begin{abstract}
Neither the massification of secondary school in Argentina since the mid-twentieth century, nor its obligation stipulated by law since 2002 , has modified its traditional scholar format, characterized as selective and exclusive. By contrast, some new schools have been created specially -and some of the old ones have been modified- to include in their classrooms social sectors previously excluded from secondary school.
\end{abstract}

\footnotetext{
* Agradezco la lectura del artículo y los comentarios realizados por la Dra. Adriana Hernández.

** Licenciada en Sociología. Universidad de Buenos Aires. Becaria Doctoral del CONICET.
} 
In this paper, we would like to work around the complexities generated from these situations, in which we can see tensions such as selection-massification, recovering problematizations around secondary school's traditional format, and the new ones that arise in this context. For this, we will analyze a Neuquén City school's pedagogic proposal, which tries to include marginalized groups from Neuquén City.

\section{Key words}

Secondary school - school pattern - massification - selection - inclusion.

\section{Introducción}

La educación secundaria es el nivel que desde sus orígenes presentó mayor complejidad en su configuración (Juarros y Capellacci, 2009) y surge especialmente como paso previo a la realización de estudios superiores, orientada a los miembros de la elite política y económica (Tenti Fanfani, 2009). Tiramonti (2011), agrega su importancia en la formación de cuadros para la administración burocrática del Estado y remarca los objetivos claramente selectivos del nivel: "Esta función selectiva está en la base de la definición de su formato y es el fundamento de una cultura escolar que naturaliza la exclusión de aquellos que no pueden responder o adaptarse a las exigencias de la institución" (p. 21-22).

Sin embargo, desde mediados del siglo XX, comenzó una apertura de la escuela secundaria a sectores sociales antes marginados de esta institución, proceso que derivó en la determinación legal de la obligatoriedad del nivel a principios de este siglo (Ziegler, 2011). Esta incorporación de nuevos grupos sociales aparece como una situación compleja en la que proliferan múltiples tensiones, entre las que destacamos en este artículo aquellas que son producto del mantenimiento del formato escolar tradicional y su masificación. Así, a modo de ejemplo, podemos pensar la manera en que la rigidez horaria y la obligación de aprobar todas las asignaturas de un ciclo para promover un año, contribuyen con el incremento de los índices de repitencia de quienes combinan la realización de estudios secundarios y el desempeño en un trabajo.

En este contexto, se registra el ensayo de diversas propuestas pedagógicas que buscan desplegar nuevas estrategias para la incorporación de dichos sectores, y que a su vez tienen efectos sobre las trayectorias de los/as jóvenes que asisten a clases. Tal pareciera ser el caso de una propuesta educativa de una escuela secundaria de la ciudad de Neuquén -que llamaremos "Escuela N"-, que recibe jóvenes provenientes de hogares de bajos recursos de dicha ciudad y presenta un énfasis en el desarrollo de prácticas de formación para el trabajo. El proyecto surge en el año 2004, por la iniciativa conjunta de una ONG, de una escuela del obispado de la ciudad y de tres sacerdotes, quienes realizaron un estudio en los barrios donde hoy está emplazada la escuela y obtuvieron como resultado que el $65 \%$ de los jóvenes en edad escolar no estu- 
diaba ni trabajaba. Además, la mayoría manifestaba que volverían a las aulas bajo la condición de que en la propuesta pedagógica se incluyeran talleres o que les enseñaran "algo concreto".

Ante este relevamiento, surgió la idea de crear un centro de formación profesional. Sin embargo, ante la importancia de tener un título secundario al momento de buscar un empleo -sumado a la obligatoriedad del nivel-, se creó en 2005 un bachillerato de cinco años de duración, en el cual además, se dictan talleres de formación para el trabajo. Depende del Obispado de la ciudad, es público pero de gestión privada y está emplazado en una de las áreas de asentamientos informales de la ciudad, en la cual es la única escuela de nivel secundario de la zona.

Por la manera en que se estructuró la propuesta pedagógica, en la que se imbricaron y modificaron dos planes de estudios, el Consejo Provincial de Educación (CPE) no reconoció la propuesta educativa bajo un único título. Por esto, los/as estudiantes egresan con una titulación de Bachiller con Orientación en Economía Social y Microemprendimientos, y una certificación de la Dirección de Adultos del CPE que reconoce 1805 horas de talleres en la especialidad correspondiente. Estas especialidades se orientan al mundo del trabajo y son: agropecuaria, diseño constructivo, informática y gastronomía.

Nos interesa reflexionar en torno a una serie de preguntas, tales como: ¿Cómo es la propuesta pedagógica de esta escuela? ¿En qué se diferencia respecto del formato tradicional de la escuela secundaria? ¿Logra cumplir con el imperativo de inclusión? ¿De qué manera? ¿Qué consecuencias tiene en las trayectorias de inserción laboral de los/as jóvenes que transitan por sus aulas? Analizaremos entrevistas realizadas a su director y a su asesor pedagógico, así como a algunos/as egresados/das de una cohorte de esta escuela, para esbozar unas primeras notas en relación con los interrogantes que nos guían.

El artículo se estructura en cuatro apartados: en el primero retomaremos tensiones y desafíos que genera la masificación y luego la obligatoriedad del nivel secundario; en el segundo trabajaremos en torno al desarrollo de nuevos formatos escolares; en el tercero intentaremos reflexionar acerca de las diversas maneras de concebir la inclusión educativa y cerraremos el trabajo presentando algunas reflexiones finales.

\section{Selección, exclusión y obligatoriedad: los problemas que se plantean.}

Como decíamos al comienzo, desde sus inicios la escuela secundaria se caracterizó por una racionalidad selectiva orientada a la formación de sectores medios y altos (Tenti Fanfani, 2007; Tiramonti, 2011), con un currículum marcadamente enciclopedista y humanista que cumplió con el ideal de una "formación general" preparatoria para el cursado de estudios universitarios, en la que ciertos saberes -como la formación para el trabajo-quedaron al margen de las propuestas pedagógicas (Southwell, 2011). 
El formato tradicional de la escuela secundaria -es decir, aquellas características que estructuran al sistema educativo moderno y que no son fácilmente modificables-, fue definido a partir de ciertos componentes, tales como la distribución de estudiantes por edades y en cursos graduales, la aprobación de casi la totalidad de las asignaturas de un ciclo para promover un grado y la organización disciplinar del currículum (Grupo Viernes, 2008).

La acotada cobertura del nivel en sus orígenes comenzó a incrementarse a partir de 1945, con una tasa de crecimiento del $10 \%$ anual hasta 1950 , mientras que en las dos décadas siguientes la matrícula siguió aumentando aunque a ritmos menos acelerados (Gallart, 1984, citado en Southwell, 2011), llegando en la década de los ' 80 a comenzar los estudios secundarios dos tercios de la población en edad teórica de iniciarlos (Southwell, 2011).

En septiembre de 2002 se estipula por ley de la obligatoriedad del nivel secundario, planteándose una encrucijada ya que, mientras que no se altera su naturaleza selectiva y excluyente -se sostiene el formato escolar tradicional-, se deben incorporar otros sectores sociales, antes marginados del sistema: "uno de los escollos mas fuertes (...) resulta del mantenimiento de la estructura pedagógica tradicional de la escuela media, tendiente a la selección por exclusión, al tiempo que se produce la apertura de este nivel a nuevos sectores sociales" (Ziegler, 2011: 74).

Con el imperativo de inclusión de los sectores sociales anteriormente excluidos, se pone de manifiesto que este formato escolar tradicional, con la obligatoriedad, la gradualidad, la evaluación y la descontextualización de los aprendizajes como dispositivos característicos, no se adecua a las particularidades y necesidades de estos grupos, que terminan por retrasarse 0 abandonar el sistema escolar (Sendón, 2011). Puntualmente, la manera en que se estructura el régimen académico -rigidez horaria y repitencia como consecuencia de la desaprobación de algunas asignaturas sin reconocimiento de las acreditadas- es postulada como una de las principales causas del abandono escolar, que aparece como uno de los grandes escollos del sistema educativo actual (Southwell, 2008).

Efectivamente, en paralelo al incremento de la escolarización de la población en el nivel medio, las tasas de deserción escolar-que habían descendido desde poco menos del $50 \%$ hasta alrededor del $30 \%$ ente 1950 y $1965-$ fueron ascendiendo de manera constante hasta superar, en la década de los '90 los valores que alcanzaban en 1950 (Giuliodori, R., Giuliodori M. y González, 2004, citado en Southwell, 2011). Estos datos ponen de manifiesto cómo, junto a las "trayectorias escolares teóricas" -entendidas como los recorridos de quienes transitan la progresión lineal que propone el sistema en los tiempos formalmente estipulados-, se despliegan trayectorias no encauzadas, que muestran recorridos biográficos que presentan quiebres y salidas del sistema escolar, 
e insumen más tiempo que el teóricamente necesario para completar el nivel (Terigi, 2007).

Pero además, la incorporación de nuevos sectores sociales al sistema educativo conlleva la diversificación mayor de los patrones culturales que circulan al interior de las instituciones como consecuencia de las pautas que aquellos grupos encarnan y reproducen (Kantor, 2010). Sin embargo, en la escuela se selecciona y transmite un capital cultural que responde a la cultura legítima y dominante (Tobeña, 2011), por lo que se produce una conversión desigual del capital. En efecto, según Bourdieu (1988) esto es consecuencia de que el capital cultural que la institución exige y transforma en capital escolar, es el que portan los "herederos" -es decir, quienes pertenecen a los sectores dominantes-. Así, el capital cultural de origen es reconocido en diverso grado en función del sector social de procedencia, y quienes provienen de hogares de bajos recursos son menos favorecidos en esta selección que quienes ocupan lugares dominantes en la estructura de clases sociales. En este sentido, Kantor (2010) plantea que la masificación del nivel no tiene como correlato la ampliación de la expectativas de las instituciones en relación con los patrones culturales de los/as estudiantes que asisten a ellas, lo cual repercute en el proceso de escolarización de los/as jóvenes, contribuyendo con la repitencia y la deserción escolar.

Se puede pensar que estamos en presencia de lo que Bourdieu (1988) denomina "formas negadas de eliminación", según las cuales la exclusión del sistema escolar de los sectores más bajos de la estructura de clases sociales no se realiza de manera explícita -por ejemplo, por medio de la prohibición del acceso a las instituciones a ciertos grupos-, sino que se produce de manera implícita y paulatina. La repitencia y el abandono escolar, serían operaciones que funcionan como mecanismos sutiles de exclusión social.

\section{Nuevos formatos escolares}

Esta tensión generada por la inclusión de sectores sociales antes marginados del sistema educativo, sin una modificación del formato escolar tradicional se resuelve, al menos provisoriamente, a partir de la creación formatos escolares novedosos. Es decir, la masificación del nivel no se realiza a través de cambios en el formato del conjunto del nivel medio (Grupo Viernes, 2008; Sendón, 2011; Ziegler, 2011), sino que el mandato social y normativo de inclusión parece ser resuelto a partir de la creación -o modificación- de algunas escuelas que se proponen alojar a quienes han sido expulsados/as de otras instituciones y que despliegan prácticas pedagógicas alternativas a las tradicionales.

En este contexto, cada escuela delinea patrones de admisión a partir de los cuales se selecciona quiénes serán admitidos y quiénes deberán asistir a otras instituciones: "las diferentes instituciones presentan un límite que demarca la población que admite retener. Cuando dicho límite es rebasado, quienes quedan por fuera deben acudir a otro tipo de institución que tenga un 
patrón de admisión más acorde" (Ziegler, 2011, p. 77). Esta característica del sistema escolar es denominada "efecto colador" por algunas investigadoras, según las cuales este sistema cuenta con circuitos escolares separados con patrones de admisión específicos, en los que se selecciona, aísla y distribuye a la población, desplegando estrategias de incorporación segregada a partir de las cuales se contiene a determinado grupo y se expulsa a los demás (Grupo Viernes, 2008). El caso de la Escuela N sería una de las instituciones creadas para incluir a quienes han sido dejar fuera de otras:

De la familia es el primer integrante en terminar la escuela secundaria o que estudia la escuela secundaria, no es un dato menor porque es una población casi analfabeta en estudios de nivel secundario... en ese sentido el barrio está un poco mejor, pero a nivel de servicios sociales hay sectores que no tiene gas, están "colgados" de la luz, (...) a nivel alimentación hay chicos que si no comen acá en la escuela no almuerzan. (Director, Escuela N).

Esta escuela se propone la inclusión de jóvenes provenientes de hogares de bajos recursos, y si bien se mantienen ciertos aspectos del formato tradicional-como la separación de los/as estudiantes por edades y la gradualidad-se presentan ciertas modificaciones y se proponen algunos mecanismos que la convierten en una propuesta novedosa respecto del formato escolar tradicional.

En este punto, resulta pertinente retomar la idea de "dispositivo" para analizar algunas de las prácticas impulsadas en la escuela, conceptualizado como "las intervenciones, enmarcadas o no dentro de políticas públicas, que se proponen explícitamente intervenir para mejorar la inserción laboral de los jóvenes" (Jacinto, 2010, p. 32). Pueden orientarse a la finalización de la escuela secundaria, a la obtención del primer empleo, a la realización de prácticas laborales o formación profesional, o a la realización de microemprendimientos (Jacinto, 2010).

Trabajaremos en torno a tres espacios -los talleres, la "Semana de la posibilidad" y el proceso de orientación vocacional que incluye a las prácticas educativas- que consideramos prácticas pedagógicas de formación para el trabajo y que, en tanto buscan incidir positivamente en la inserción de los/as estudiantes en el mundo del trabajo, podrían ser definidas en los términos que Jacinto (2010) entiende al dispositivo.

El primer dispositivo son los talleres. Si bien el currículum se construye a partir de una concatenación de asignaturas organizadas disciplinariamente, y que conforman el Bachillerato con orientación en Economía Social y Microemprendimientos, además deben cursar y aprobar los talleres orientados al mundo del trabajo, certificados por la Dirección de Adultos del CPE. Durante los primeros dos años de escolaridad, los/as jóvenes rotan por todos los talleres -agropecuaria, gastronomía, diseño constructivo e informática-, en 
$3^{\circ}$ año eligen una orientación y en grupos, redactan un proyecto para realizar un microemprendimiento durante los dos ciclos lectivos restantes. En estos espacios, suelen producirse situaciones de trabajo reales, tal como las que nos contaba el director:

En gastronomía, una de las profes coordina (...) el cáterin. Tenemos toda la vajilla, manteles, cofias, delantales, trajes, y tenemos toda la instalación para hacerlo, así que los chicos... no muy seguido, pero cumpleaños de 15, casamientos, eso hacen los chicos. (Director, Escuela N).

De un programa de nación, (...) nos pidieron 400 viandas por día, que hay que garantizar. Así que la escuela está haciendo 400 viandas por día, en el trascurso de dos meses para esto... lo entregamos en la puerta de la escuela, vienen a retirarlo y se nos pagan por vianda, entonces está trabajando de $1^{\circ}$ a $5^{\circ}$ año (...). Pero bueno, eso implica todo un movimiento en la escuela de que hay que sacar alumnos de la mañana de $3^{\circ}$ y $4^{\circ}$ para que den una mano con la profe a $1^{\circ}$ y $2^{\circ}$, ya a la tarde sí están los cursos de gastronomía. (...) Pero nos implica sacar a la mañana dos o tres alumnos de $3^{\circ}$ y dos o tres alumnos de $4^{\circ}$. Por ahí hay que hablar con el docente que no se repitan los días para que no le afecte todos los días la misma materia. (...) Todo un entretejido, pero da muy buenos... y ahí nosotros estamos totalmente convencidos que se pueden hacer emprendimientos reales. (Director, Escuela N).

En estas citas se puede ver cómo los/as jóvenes participan de situaciones de trabajo reales, enmarcadas en actividades impulsadas desde la propia institución. En ellas, se modifica la propia dinámica escolar cotidiana, ya que en algunos casos los/as estudiantes se trasladan fuera del aula -e incluso de la escuela- para realizar ciertos aprendizajes y por otro implica la enseñanza de distintos contenidos de manera contextualizada.

Otro dispositivo de la escuela es el desarrollo de un proceso de orientación vocacional y la realización de prácticas educativas en lugares de trabajo. La orientación vocacional comienza en $4^{\circ}$ año -reciben docentes y estudiantes de la carrera de psicología que les administran algunas pruebas a los/as jóvenes-y culmina a mediados de $5^{\circ}$ año cuando tienen una entrevista con los referentes del proyecto en la institución -una docente de la escuela y el asesor pedagógico-. A lo largo del proceso se van trabajando los intereses, aspiraciones, visión de futuro, deseos y expectativas de los/as jóvenes y, a fines de $5^{\circ}$ año, algunos/ as estudiantes -alrededor del $50 \%$, seleccionados/as en función de la cantidad de materias aprobadas y de inasistencias-, acceden a prácticas educativas en distintas instituciones, organizaciones y empresas -como escuelas de música, 
cafés, estudios de abogados, fábricas, talleres mecánicos, entre otros- donde también realizan prácticas laborales situadas en contextos reales:

Una de las cosas que cierra este proceso de orientación vocacional son las prácticas educativas. Que no... no son elegidas por el docente, como pueden ser en otro colegio, sino que a partir de este proceso y principalmente una entrevista que se le realiza al chico digamos, donde se ponen en juego las expectativas del joven, su futuro, qué cosas le interesarían seguir... a partir de esa entrevista se eligen, o se consigue una organización, una institución donde pueda hacer esta práctica educativa. (Asesor pedagógico, Escuela N).

Estas prácticas, junto a los aprendizajes realizados en el marco de los talleres y de los microemprendimientos, suelen ser rescatados por los/as egresados/as como actividades enriquecedoras respecto de la formación para el mundo del trabajo:

El emprendimiento surgió a partir de la escuela. Quise criar vacas, pero no me dejaron, entonces propuse criar chanchos y tampoco me dejaban... por el olor... entonces les digo que yo me voy a hacer cargo, que voy a limpiar el chiquero... en esa época estaba medio colgado en la escuela, pero insistí mucho hasta que me dejaron. Todo lo que aprendía sobre animales en la escuela, así, toda la teoría, lo aplicaba en mi casa, donde ya habíamos empezado a criar chanchos. (Egresado Escuela N, 19 años de edad, estudia Profesorado en Educación Física, trabaja en un criadero de cerdos familiar).

Lo que más me sirvió de la escuela para trabajar fue lo que aprendí de electricidad en $2^{\circ}$ año. Eso me gustó y me interesó y entonces seguí estudiando más. (Egresado Escuela N, trabaja de electricista).

Por último, otro dispositivo es la "Semana de la posibilidad". Son tres semanas distribuidas a lo largo del ciclo lectivo, en las que se suspende la actividad académica cotidiana, por lo que producen modificaciones respecto del uso del tiempo y del espacio escolar. En ellas, los/as estudiantes de $1^{\circ}, 2^{\circ}$ y $3^{\circ}$ año con bajas calificaciones permanecen en las aulas para recuperar contenidos y de esta manera evitar el retraso. Paralelamente, quienes han aprobado los contenidos de las materias, realizan diversos talleres de capacitación para el trabajo relacionados con las orientaciones que han elegido, o bien asisten a cursos de formación artística o deportiva, acompañados por docentes de la escuela y por personas ajenas a la institución invitadas a participar en estas jornadas -en general, especialistas en diversas temáticas-. A modo de ejemplo, en la orientación gastronomía han impartido cursos de cáterin, de sommellier y de camarero; en el marco de diseño constructivo, hubo talleres de construcción de paneles solares, para aprender a utilizar ciertas herramientas o equipos y de 
construcción natural; en la especialidad de agropecuaria han realizado capacitaciones relativas a parques y jardinería y de apicultura, y finalmente, en el área de informática han dictado cursos de reparación y operador de PC -este último abierto a la comunidad-. En cuanto a los talleres deportivos y artísticos, enseñan técnicas para hacer murales, esculturas, macramé, decoración de tortas, enseñan murga, circo, pin-pon, entre otros. Además, durante estas semanas hacen un taller solidario en el cual se realizan intervenciones en el barrio -en general, tres por semana-, en las que se ayuda de distinta manera a vecinos/ as, familiares de los/as jóvenes, etc. Así la describía el director:

Una semana especial, que se llama la Semana de la posibilidad, (...) no están los cursos así armados como en el transcurso del año. Hay chicos que están recuperando en el aula en esa semana y otros están haciendo talleres. Justamente esto, para el mundo del trabajo. Talleres especiales, artístico alguno, otros de las especialidades que tenemos acá en la escuela. (Director, Escuela N).

Los chicos de $1^{\circ}$, "2 y $3^{\circ}$ que tiene que recuperar van al aula, y con todo el resto de la escuela generalmente ciclo superior tienen que hacer las capacitaciones de los talleres en los cuales están... están yendo ellos, que eligieron bah. Entonces son cinco días de cinco horas reloj, son veinticinco horas por semana, es mucha carga horaria y entonces está muy bueno. $Y$ con los $1^{\circ}$ y $2^{\circ}$ que no van al aula se hacen distintos talleres más bien artísticos: mural, murga, escultura, circo, pin-pon, macramé. (Director, Escuela N).

Durante estos ciclos, la escuela cambia su dinámica cotidiana por otra en la que los cursos se desarman y se constituyen grupos según los intereses de los/as jóvenes que eligen el taller del que desean participar. Además, en estos periodos se interviene activamente en el barrio, realizando distintas tareas, como ayudar a terminar una casa a un vecino, construir hornos de barro, etc.:

Hay chicos que con la semana esa de la experiencia solidaria, yo digo "no puede ser", cuando vos los cambiás es increíble. Vos lo sacás del contexto del aula y va al barrio y se ponen a trabajar y se ponen a hacer... las chicas (...) se ponen a hacer torta fritas, le limpiaron la casa al abuelo esa vez que le hicimos a un abuelito ahí que... medio discapacitado, hicimos las bases. Ahora también, gracias a nosotros, a la escuela, nos empezamos a mover... una mamá... conseguimos distintos contactos y le hicimos la platea, el contrapiso y como un bañito, tratamos en esa semana levantar eso. Entonces hicimos distintos contactos y no sé, se enteró un concejal... así que bueno, él vino, puso la plata y la terminó de levantar. Bueno, la cosa es que nosotros hicimos los cimientos, y ya está techado. En mayo empezó y ahora en agosto ya estaba terminada la casita del abuelo. 
También eso, como desde la escuela vos generas... como se abren otras puertas también, para la gente del barrio y... después, construcción natural que le han hecho un horno de barro a una familia, que no tienen gas por ejemplo. (Director, Escuela N).

Por otra parte, en la institución hay cierta flexibilidad respecto de las inasistencias a clases. En efecto, hay alumnos/as que en las estadísticas oficiales del CPE aparecen como libres -por exceso de inasistencias-, pero en la práctica continúan yendo a la escuela y cursando las materias. Luego, si aprueban los contenidos de las asignaturas, se los/as anota como si hubieran promovido las materias en instancias de exámenes libres, y además pueden continuar realizando los emprendimientos de que participan. Sin embargo, esta situación plantea ciertas contradicciones en relación con la instrucción en conductas valoradas socialmente al momento de conseguir un empleo, tales como la puntualidad:

Hay alumnos que no están como alumno regular. Pueden seguir viniendo al colegio, pueden seguir instancias evaluativas. [...] Siguen teniendo sus emprendimientos, no los inhabilita a estar en el colegio. Siguen estando en el colegio. Se relaciona con la metodología que plantea la escuela, que tiene que ver con flexibilizar ciertas cuestiones formales que hacen a la inclusión educativa y al sostenimiento de los chicos en la escuela. El problema es que puede generar una inasistencia crónica. (Asesor pedagógico, Escuela N).

Si bien la gradualidad característica del formato tradicional se mantiene, se implementan algunas estrategias que permiten franquear ciertas medidas que pueden derivar en deserción escolar.

\section{Inclusión educativa: distintas maneras de ser parte.}

A partir de las características de la escuela y de las voces recuperadas, se puede plantear entonces, que la Escuela $\mathrm{N}$ despliega prácticas pedagógicas que constituyen un formato escolar distinto del tradicional, por medio de las cuales intenta lograr la inclusión educativa y social de los/as jóvenes que concurren. Ahora bien, ¿Qué significa estar incluido? Para Sendón (2011), la inclusión puede ser entendida de distintas maneras: como inclusión pedagógica, como inclusión social o bien, como disciplinamiento.

En el primer caso, la transmisión de nuevos saberes es el eje a partir del cual se desarrolla la socialización, la educación es entendida como un derecho y se despliegan, entonces, estrategias que se adecuan a las realidades de quienes transitan por las aulas. La segunda posibilidad se relaciona con la idea de alojar a los jóvenes en situaciones en que los accesos a otros ámbitos -como el mundo del trabajo- están vedados o las posibilidades son precarias, y el rol 
más importante de la institución es entonces la contención social. Por último, si la inclusión es entendida como disciplinamiento del cuerpo y dispositivo de control social, la institución debe disciplinar y controlar a quienes, por sus condiciones sociales y afectivas, son una "amenaza" para el orden social. Este "déficit" de los/as estudiantes trae como consecuencia que el objetivo sea la retención y la instrucción en algunas reglas básicas de convivencia, más allá de los saberes que la escuela secundaria debe impartir (Sendón, 2011). Para el caso de esta escuela, el director nos decía que:

Hay saberes que sí o sí tienen que estar, y la escuela media (...) ha caído más como en la contención del adolescente, y con que aprenda algo, que pase. Para nosotros al principio era más así. Había muchas facilidades para que el chico egrese y promocione. Ahora estamos cada vez más exigentes. No sé si un saber enciclopedista, pero sí que pueda razonar y pensar y que tenga herramientas para que se pueda desenvolver, y eso implica un proceso mental, un proceso cognitivo, que de acuerdo a la estrategia pedagógica que uno desarrolle en la escuela lo lográs o no. Y eso es lo que nosotros intentamos. (...) Y después las habilidades propias, que nosotros insistimos mucho, que es la higiene, la seguridad, la puntualidad, la constancia. (...) Pero si me pongo muy exigente, me quedo con la mitad de los alumnos." (Director, Escuela N).

La escuela fue pasando de un primer momento de contención, a uno de inclusión, a educación. Como distintos paradigmas año tras año. De la inclusión no nos tenemos que preocupar porque tenemos una lista de 150 [inscriptos a $1^{\circ}$ año] y pueden ingresar 60 . (...) De contención sí estamos trabajando mucho para que el chico esté en la escuela, y quede, y egrese. No es sencillo, por el contexto... Para nosotros es bajo, pero para los índices de la escuela media es alto, casi el $60 \%$ de los que ingresan, terminan. (...) Es por el trabajo de seguimiento que se hace, la idea de la escuela es no crecer más de 300 alumnos, de 10 cursos; primero porque no tenemos los recursos humanos, y si los tuviéramos, no llegás a conocer personalmente al alumno como lo conocemos ahora. Y eso tiene que ver en la inclusión, tiene que ver en la contención del alumno en la escuela. (Director, Escuela N).

A partir de las citas, podemos ver cómo las tres formas de inclusión aparecen entrelazadas en la propuesta de la escuela. Por un lado, encontramos la función de contención social de los/as jóvenes, el intento de que se mantengan dentro de la institución. Por otro, el disciplinamiento como inculcación de normas socialmente aceptadas y valoradas, como el aseo personal y la responsabilidad -a partir de las exigencias de puntualidad y constancia-. Por último, la inclusión pedagógica marcada como las exigencias en relación con ciertos conocimientos 
que les permitan a los/as jóvenes resolver diversas situaciones en sus vidas cotidianas, pretensiones incorporadas luego de lograr cierta contención de los/ as estudiantes en la escuela.

Además, aparece el seguimiento personalizado de los/as jóvenes como una estrategia para incluir y retener a los/as estudiantes en la institución, por medio de relaciones de proximidad que los/as trabajadores/as de la escuela buscan entablar, lo cual es posible gracias al número relativamente reducido de alumnos/as. Esta importancia de las relaciones cara a cara es valorada positivamente tanto por el cuerpo directivo, por los/as docentes como por los/as estudiantes. De acuerdo con los planteos de Montes y Ziegler (2010) respecto de los beneficios que traen este tipo de relaciones para efectivizar la escolaridad, pensamos que este seguimiento se presenta como una condición necesaria para que los alumnos desarrollen sus procesos de aprendizaje: reiterando explicaciones, buscando alternativas pedagógicas que involucren a los estudiantes en las clases, etc. La contención emocional, el seguimiento personalizado y las ayudas extraacadémicas que reciben "hasta del portero" -según la voz de un egresado-, aparecen como algunas de las prácticas que contribuyen con la retención de los/as jóvenes dentro de la institución, y con ello a la inclusión educativa buscada.

Por último, nos interesa rescatar las ideas planteadas en relación con la clase de sujeto que les interesa formar en la escuela. Se trata de formar emprendedores, sujetos que se constituyan como agentes de su propio destino, despertando "la potencia emprendedora":

"Cuando ellos se dan cuenta que pueden, que convierten su historia negativa, sus problemas, y se dan cuenta que pueden, se les levanta el autoestima y no los para nadie, porque vienen de abajo y saben lo que es sufrir. (...) La idea es que como egresado salga un joven emprendedor, no que se vaya a poner a criar chanchos... si lo hace, perfecto, pero sí con la mentalidad de emprender." (Director, Escuela N).

Este intento de formar jóvenes emprendedores implica el desarrollo de la agencia como característica personal, y creemos que contribuye en la formación de sujetos críticos, operando positivamente en la inclusión social.

\section{Reflexiones finales}

Para finalizar, nos gustaría realizar algunos comentarios que surgen luego de presentar el caso a la luz de las discusiones planteadas. En primer lugar, si bien la discusión en torno a la inclusión no se reduce a la cuestión de la cobertura, sino que a este aspecto debemos sumarle los debates en torno a la calidad, resulta un avance en todo sentido la existencia de una escuela secundaria en una zona de la ciudad donde previamente a su creación no 
había ninguna institución de nivel medio, y cuya necesidad se manifiesta en la cantidad de familias que actualmente intentan que sus hijos/as ingresen a la escuela y no lo logran por la falta de vacantes. Su emplazamiento en esta área favorece la asistencia a la escuela secundaria de muchos/as jóvenes que antes quedaban fuera de la escuela.

En segundo lugar, diversos aspectos de la propuesta pedagógica, como el seguimiento personalizado que se realiza de los/as estudiantes, la posibilidad de continuar con los estudios -tanto de las asignaturas curriculares como de los microemprendimientos- a pesar de que queden libres por inasistencias, el cursado de talleres o la realización de proyectos productivos, parecen beneficiar la permanencia de los/as jóvenes en la institución y con ello la terminalidad de la escuela secundaria, así como la consecución de estudios superiores, ya sean terciarios o universitarios - de hecho, varios de los/as egresados/as entrevistados/as se encuentran estudiando en instituciones terciarias y universitarias, tanto públicas como privadas-.

En tercer lugar, el pasaje por los dispositivos señalados así como la orientación de la escuela, implica una formación más amplia en relación con el mundo laboral en la cual se brindan saberes y competencias específicas -como la formación para la realización de proyectos productivos, la identificación de condiciones de contratación de calidad, la determinación del precio justo de los productos de sus trabajos, entre otros-. Sin embargo, y aunque ésta es una discusión que excede los límites del presente artículo, entendemos que la formación por sí sola no resuelve la inserción laboral de los/as jóvenes en un mercado de trabajo juvenil caracterizado como precario (Pérez, 2010).

Por último, a partir de todo lo trabajado en el artículo, podemos decir que con la obligatoriedad del nivel secundario estipulada por ley, también se vuelve legamente obligatoria la demanda de inclusión educativa de todos los sectores, que implica una inclusión más amplia que es la inclusión social. Sin embargo, para que esto sea posible, el camino para lograrlo no es la búsqueda de la "normalización de las trayectorias" -es decir, el intento de que las trayectorias reales se asemejen a las teóricas-, sino que la vía para alcanzarla es la ampliación, diversificación y flexibilización del espectro de trayectorias posibles (Terigi, 2007). Y es este el objetivo que parecería proponerse alcanzar la Escuela $\mathrm{N}$ : no que los/as jóvenes se adapten a un formato escolar caracterizado como selectivo y excluyente, sino que la escuela amplíe y modifique su propuesta educativa para incorporar a los sectores relegados, produciendo ciertas fracturas en las lógicas de exclusión social:

Con las herramientas que ya han adquirido en el secundario, se pueden defender muy bien. Hay un chico en la meseta que entró a trabajar de soldador y está dando clases, un taller. Es más, vino a pedirme si no le prestaba una soldadora. Es genial que un chico que estaba en el basural, juntando basura, y que después de 5 años, 
esté dando clases en la escuela primaria a donde él fue... Es cierto, es uno... pero es uno. (Director, Escuela N).

\section{Referencias Bibliográficas}

- $\quad$ Bourdieu, P. (1988). La distinción. Criterio y bases sociales del buen gusto. Madrid: Taurus.

- Grupo Viernes (2008). Una experiencia de cambio en el formato de la escuela media: las Escuelas de Reingreso en la Ciudad de Buenos Aires. Revista Propuesta Educativa, 17 (30), 57-69.

- Juarros, F. y Cappellacci, I. (2009). El proceso de democratización del nivel medio en el sistema educativo argentino. Espacios de crítica y producción, 40, 88-95.

- Jacinto, C. (2010). Introducción. Elementos para un marco analítico de los dispositivos de inserción laboral de jóvenes y su incidencia en las trayectorias. En C. Jacinto, (comp.). La construcción social de las trayectorias laborales de jóvenes. Políticas, instituciones, dispositivos y subjetividades (15-49). Buenos Aires: Teseo / IDES.

- Kantor, D. (2010). Escuela media y "condición juvenil”. Distancias, aproximaciones, sentidos. Clase 9 Seminario virtual de FLACSO.

- Montes, N. y Ziegler, S. (2010). Miradas sobre una experiencia de cambio en la escuela secundaria. Nuevos formatos para promover la inclusión educativa. Revista Mexicana de Investigación Educativa, 15 (47), 1075-1092.

- $\quad$ Pérez, P. (2010) ¿Por qué difieren las tasas de desempleo de jóvenes y adultos? Un análisis de las transiciones laborales en la Argentina post Convertibilidad. En J. Neffa, D. Panigo, y P. Pérez (comps.). Transformaciones del empleo en la Argentina. Estructura dinámica e instituciones (pp. 77-104). Buenos Aires: CICCUS/CEIL-PIETTE.

- Sendón, M. A. (2011). El imperativo de la inclusión escolar y la proliferación de significados acerca de la escolarización secundaria. En G. Tiramonti (dir). Variaciones sobre la forma escolar. Límites y posibilidades de la escuela media (pp. 155-178). Rosario: Homo Sapiens Ediciones, Buenos Aires: FLACSO.

- Southwell, M. (2008). ¿Particular? ¿Universal? Escuela media, horizontes y comunidades. Revista Propuesta Educativa, 17 (30), 23-35.

- Southwell, M. (2011). La educación secundaria en la Argentina. Notas sobre la historia de un formato. En G. Tiramonti (dir). Variaciones sobre la forma escolar. Límites y posibilidades de la escuela media (pp. 35-70). Rosario: Homo Sapiens Ediciones. Buenos Aires: FLACSO.

- Tenti Fanfani, E. (2007). La escuela y la cuestión social. Ensayos de sociología de la educación. Buenos Aires: Siglo XXI.

- Tenti Fanfani, E. (2009). La enseñanza media hoy: masificación con exclusión social y cultural. En G. Tiramonti y N. Montes (comp.). La escuela media en debate. Problemas actuales y perspectivas desde la investigación (pp. 53-69) Buenos Aires: Manantial / FLACSO.

- $\quad$ Terigi, F. (2007). Los desafíos que plantean las trayectorias escolares. Trabajo presentado en el III Foro Latinoamericano de Educación. Jóvenes y docentes. La escuela secundaria en el mundo de hoy, 28 al 30 de mayo, Buenos Aires.

- Tiramonti, G. (2009). Una aproximación a la dinámica de la fragmentación del sistema educativo argentino. Especificaciones teóricas y empíricas. En G. Tiramonti y N. Montes (comp.). La escuela media en debate. Problemas actuales y perspectivas desde la investigación (pp. 25-38) Buenos Aires: Manantial / FLACSO. 
- Tiramonti, G., (2011). Escuela media: la identidad forzada. En G. Tiramonti (dir). Variaciones sobre la forma escolar. Límites y posibilidades de la escuela media (pp. 17-34). Rosario: Homo Sapiens Ediciones, Buenos Aires: FLACSO.

- Tobeña, V. (2011). La escuela en el mundo contemporáneo. Notas sobre el cambio cultural. En G. Tiramonti (dir). Variaciones sobre la forma escolar. Límites y posibilidades de la escuela media (pp. 205-237) Rosario: Homo Sapiens Ediciones, Buenos Aires: FLACSO.

- Ziegler, S. (2011). Entre la desregulación y el tutelaje: ¿hacia dónde van los cambios en los formatos escolares? En G. Tiramonti (dir). Variaciones sobre la forma escolar. Límites y posibilidades de la escuela media (pp. 71-88). Rosario: Homo Sapiens Ediciones, Buenos Aires: FLACSO. 